\title{
Oxygen dissociation curve in Eales's disease
}

\author{
D. L. BOASE, ${ }^{1}$ R. E. GALE, ${ }^{2}$ AND E. R. HUEHNS ${ }^{2}$ \\ From the ${ }^{1}$ Oxford Eye Hospital, Walton Street, Oxford (formerly at Moorfields Eye Hospital, \\ City Road, London), and the ${ }^{2}$ Department of Clinical Haematology, University College \\ Medical School, London
}

SUMMARY The oxyhaemoglobin dissociation curve (ODC) was investigated in 15 patients with Eales's disease and 11 controls to test the hypothesis that Eales's disease is caused by retinal hypoxia secondary to impaired oxygen release from the blood. Patients with the peripheral form of Eales's disease did not have any significant difference in their $\mathbf{P}_{50}$ values when compared with the controls. However, the $P_{50}$ values were significantly lower $(P<0.005)$ for the patients with mixed retinopathy. This degree of increased oxygen affinity is not physiologically significant but may reflect an intrinsic abnormality of the red cells in these cases.

Retinal perivasculitis is a descriptive term applied to conditions where there is sheathing and occlusion of the retinal vessels which may be associated with retinal haemorrhages, new vessel growth, and vitreous haemorrhages which ultimately lead to retinal detachment, cataract, and glaucoma. Many of these cases are secondary to uveitis or systemic disease, but in the majority retinal perivasculitis occurs as a primary or idiopathic condition of the eye. These patients may be considered to have Eales's disease, since they typify his original description $^{12}$ of 'primary retinal haemorrhages in young men'. This appears to be a noninflammatory condition and is the subject of this paper. However, it must be stressed that Eales's disease is a descriptive term which probably shelters many entities.

Eales's disease usually affects healthy males between the ages of 20 and 30 years, but it may occur at any age and also in females. The clinical appearances may range from those of peripheral vessel closure and new vessel growth resembling sickle cell retinopathy (Fig. 1) to those of diffuse vascular disease and disc neovascularisation similar to diabetic retinopathy (Fig. 2). The disease is often characterised by tortuosity, beading, and sheathing of the vessels. Both eyes are usually affected, but the condition may be unilateral.

Despite prolonged interest ${ }^{3}$ the aetiology of Eales's disease remains obscure. However, the clinical picture suggests a hypoxic process affecting the retina. Factors involved in tissue oxygenation include pulmonary function, cardiac output, and

Correspondence to Mr D. L. Boase, Oxford Eye Hospital, Walton Street, Oxford. the oxygen affinity of the blood. Patients with Eales's disease apparently have normal cardiac and pulmonary function, so we decided to investigate the oxygen affinity of their blood.

\section{Hypothesis}

Impaired oxygen release from the erythrocytes may be a factor in the aetiology of Eales's disease.

In man, oxygen is transported bound to haemoglobin within the erythrocytes. Haemoglobin exists in 2 forms, oxyhaemoglobin and deoxyhaemoglobin, and the relationship of the 2 is best described by the oxyhaemoglobin dissociation curve (ODC, Fig. 3 ), in which the percentage oxygen saturation of haemoglobin is plotted against the partial pressure of oxygen. The ODC has a sigmoid shape because the affinity of haemoglobin for oxygen increases as the molecules of oxygen sequentially combine. This provides a very efficient oxygen transport system because at alveolar oxygen tension $\left(\mathrm{PO}_{2}{ }^{90-100}\right.$ $\mathrm{mmHg}$ ) the curve is flat and the oxygen tension has to fall by $25-30 \mathrm{mmHg}$ before there is significant oxygen release. The ODC has a steep slope at tissue $\mathrm{Po}_{2}$ (approximately $40 \mathrm{mmHg}$ ) and a small change in oxygen tension would have a large effect on oxygen release. Oxygen affinity is usually indicated by the $P_{50}$ value which is that $\mathrm{Po}_{2}$ at which the haemoglobin is half saturated. Under standard conditions of $37^{\circ} \mathrm{C}$ temperature and $\mathrm{pH} 7.4$ the $\mathbf{P}_{50}$ value for normal whole blood is $26.6 \mathrm{mmHg}$.

An increase in oxygen affinity (low $P_{50}$ ) means that less oxygen is released for a given fall in $\mathrm{Po}_{2}$ and will shift the ODC to the left. Conversely a decrease in oxygen affinity (high $\mathbf{P}_{50}$ ) means that 


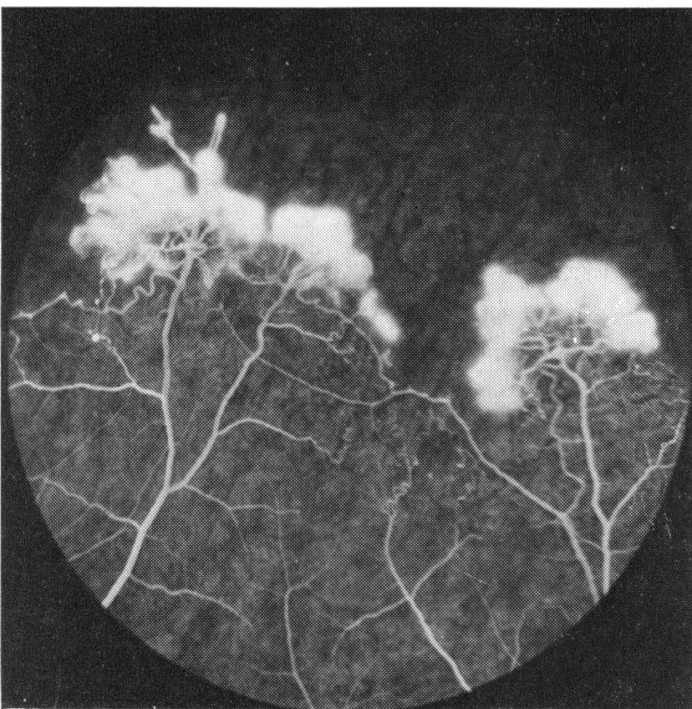

Fig. 1 Case 4, peripheral vessel closure and new vessel growth resembling sickle cell retinopathy.

more oxygen is released for a given fall in $\mathrm{PO}_{2}$ and there is a right shift of the ODC.

The oxygen affinity of the blood not only reflects the intrinsic nature of the haemoglobin but is also subject to modification by certain intracellular ligands. These include hydrogen ions, carbon dioxide, and organic phosphates, especially 2,3diphosphoglycerate (2,3-DPG). Hydrogen ions and carbon dioxide decrease oxygen affinity (high $\mathbf{P}_{50}$ ) with a right shift in the ODC. Alkalosis increases oxygen affinity (low $P_{50}$ ) and the ODC shifts to the left. The shift in the position of the ODC caused by pH change is known as the Bohr effect. 2,3-DPG is an organic phosphate produced by red cell glycolysis. It reduces oxygen affinity by combining preferentially with deoxyhaemoglobin and through the Bohr effect by lowering the intraerythrocyte $\mathrm{pH}$. The rate of erythrocyte glycolysis is geared to produce a level of 2,3-DPG that will oppose any shift in the ODC. For example, the level of 2,3-DPG is low in acidotic states.

Factors involved in oxygen transport include pulmonary function, cardiac output, haemoglobin concentration, and oxygen affinity. These are in equilibrium in order to maintain normal tissue oxygenation, and when one is altered the others compensate. For example, in anaemia there is an increase in breathing and cardiac output. There is also an increase in the level of 2,3-DPG in the erythrocytes, which shifts the ODC to the right (high $\mathbf{P}_{50}$ ) and so decreases the oxygen affinity. Erythrocytes with abnormal oxygen affinity com-

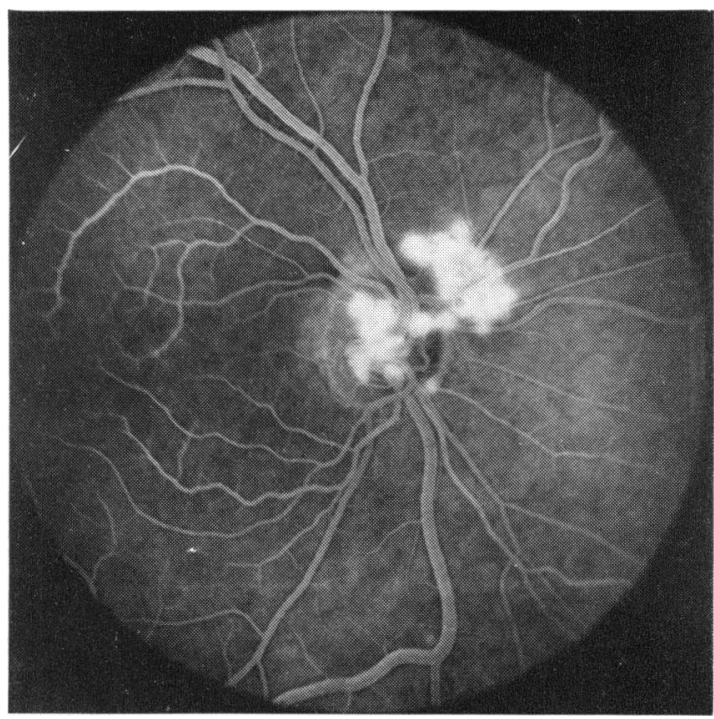

Fig. 2 Case 12, disc neovascularisation similar to diabetic retinopathy.

pensate by changes in their haemoglobin concentration. Low oxygen affinity (ODC shifted to the right, high $\mathbf{P}_{50}$ ) causes the haemoglobin concentration to be lower, whereas high oxygen affinity (ODC shifted to the left, low $P_{50}$ ) causes an increased haemoglobin concentration. This compensatory response is mediated through the haemopoietic system.

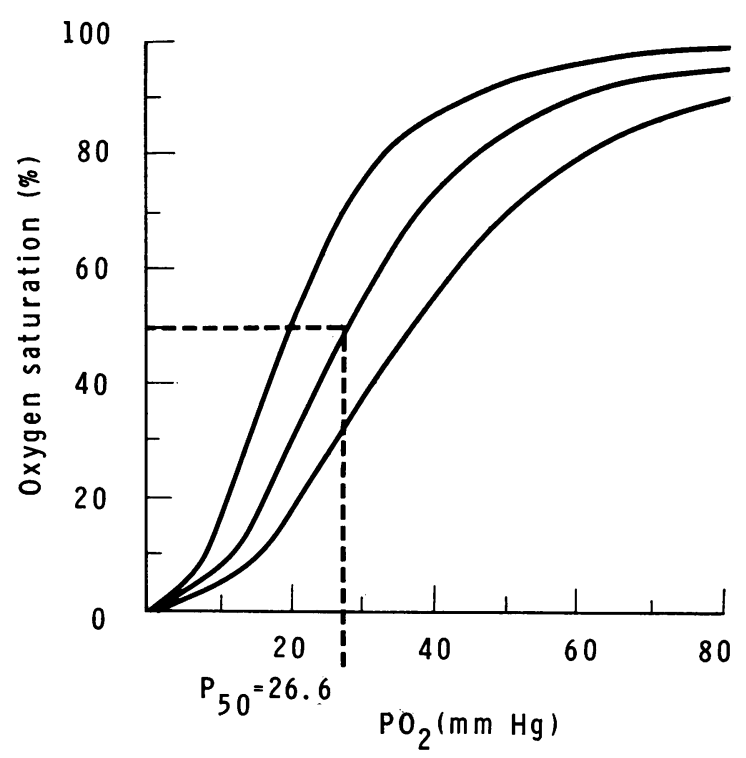

Fig. 3 The oxyhaemoglobin dissociation curve $(O D C)$ illustrating the effects of left and right shifts. 
Table 1 Patients with Eales's disease

\begin{tabular}{|c|c|c|c|c|c|c|c|c|c|c|}
\hline Case & Age & Sex & $\begin{array}{l}\text { Type of } \\
\text { Eales }\end{array}$ & $\begin{array}{l}H b \\
(g / d l)\end{array}$ & $P C V$ & Retics & $\begin{array}{l}P_{50} \\
(m m H g)\end{array}$ & $n$ & $\begin{array}{l}D P G \\
(\mu \mathrm{mol} / \mathrm{g})\end{array}$ & $\begin{array}{l}\text { Hb } \\
\text { electrophoresis }\end{array}$ \\
\hline 1 & 25 & $\mathbf{M}$ & Mixed & $15 \cdot 5$ & 47 & $1 \cdot 6$ & $29 \cdot 0$ & $2 \cdot 8$ & $11 \cdot 68$ & $\mathbf{A A}$ \\
\hline 2 & 57 & $\mathbf{F}$ & Mixed & $15 \cdot 6$ & 45 & $2 \cdot 6$ & $29 \cdot 0$ & $2 \cdot 8$ & $11 \cdot 16$ & $\mathbf{A A}$ \\
\hline 3 & 44 & $\mathbf{M}$ & Mixed & $16 \cdot 6$ & 48 & $1 \cdot 0$ & $28 \cdot 0$ & $2 \cdot 9$ & $12 \cdot 00$ & $\mathbf{A A}$ \\
\hline 4 & 38 & $\mathbf{F}$ & Peripheral & $15 \cdot 4$ & 45 & $1 \cdot 2$ & $28 \cdot 0$ & $2 \cdot 8$ & $16 \cdot 74$ & $\mathbf{A A}+$ Hb F $3 \%$ \\
\hline 5 & 23 & $\mathbf{M}$ & Mixed & 14.9 & 44 & 0.4 & $28 \cdot 0$ & $2 \cdot 3$ & $10 \cdot 42$ & $\mathbf{A A}$ \\
\hline 6 & 55 & $\mathbf{M}$ & Mixed & $15 \cdot 00$ & $45 \cdot 5$ & $0 \cdot 4$ & $28 \cdot 5$ & $2 \cdot 7$ & $15 \cdot 04$ & $\mathbf{A A}$ \\
\hline 7 & 38 & $\mathbf{M}$ & Mixed & $17 \cdot 2$ & $49 \cdot 6$ & $0 \cdot 6$ & $28 \cdot 5$ & $2 \cdot 7$ & $13 \cdot 76$ & $\mathbf{A A}$ \\
\hline 8 & 36 & $\mathbf{F}$ & Peripheral & $11 \cdot 2$ & $33 \cdot 5$ & $0 \cdot 8$ & $28 \cdot 0$ & $2 \cdot 8$ & $15 \cdot 33$ & Hb AD \\
\hline 9 & 48 & $\mathbf{M}$ & Peripheral & $16 \cdot 0$ & $45 \cdot 5$ & $1 \cdot 0$ & $30 \cdot 0$ & $2 \cdot 5$ & $13 \cdot 22$ & AA \\
\hline 10 & 38 & $\mathbf{M}$ & Peripheral & $14 \cdot 2$ & $41 \cdot 1$ & $1 \cdot 0$ & $31 \cdot 0$ & $3 \cdot 0$ & 13.95 & $\mathrm{AA}+5 \% \mathrm{Hb} F$ \\
\hline 11 & 34 & $\mathbf{F}$ & Mixed & $13 \cdot 4$ & $40 \cdot 3$ & $0 \cdot 2$ & $29 \cdot 5$ & $2 \cdot 7$ & $17 \cdot 07$ & $\mathbf{A A}$ \\
\hline 12 & 51 & $\mathbf{M}$ & Mixed & $16 \cdot 6$ & $50 \cdot 0$ & $0 \cdot 4$ & $27 \cdot 5$ & $2 \cdot 7$ & $12 \cdot 47$ & $\mathbf{A A}$ \\
\hline 13 & 50 & $\mathbf{M}$ & Peripheral & $15 \cdot 7$ & $43 \cdot 0$ & $1 \cdot 2$ & $31 \cdot 0$ & 2.7 & $15 \cdot 38$ & $\mathbf{A A}$ \\
\hline 14 & 64 & $\mathbf{M}$ & Peripheral & $14 \cdot 4$ & $43 \cdot 0$ & 0 & $27 \cdot 5$ & $2 \cdot 6$ & 10.9 & $\mathbf{A A}$ \\
\hline 15 & 46 & $\mathbf{M}$ & Peripheral & $13 \cdot 8$ & $42 \cdot 0$ & 0 & $30 \cdot 25$ & 2.9 & $14 \cdot 34$ & $\mathbf{A A}$ \\
\hline
\end{tabular}

$\mathbf{P}_{50}$, washed red cells at pH 7.00; normal 29.5-32.00 mmHg. n, Hill's constant; normal 2.6-2.9.

Although these compensatory responses are adequate in general, the retina may become hypoxic (in cases with impaired oxygen release) owing to the special nature of its circulation and metabolism. The retina is particularly vulnerable to hypoxia due to the small calibre and endarterial nature of its blood supply, which has to function at pressures above the intraocular tension. Moreover the retina has a very high metabolic rate, which requires a rich oxygen supply. Retinal hypoxia would be worse on the venous side of the capillary bed and would cause dilatation of the vessels with slowing of blood flow. This combined with a raised haematocrit would increase the viscosity in these vessels and may lead to their occlusion. Hypoxia may also damage the vessel walls directly and cause thickening and proliferation of the endothelium with ultimate occlusion. This pathogenesis has been suggested for diabetic retinopathy by Ditzel. ${ }^{4}$ New vessels would grow in response to retinal hypoxia and may cause recurrent vitreous haemorrhages, so fulfilling the criteria for Eales's disease.

\section{Patients and methods}

Fifteen patients with Eales's disease were studied. These were all cases of retinal neovascularisation of unknown aetiology without associated systemic disease or uveitis. In particular, diabetes, hyperten- sion, sickle cell disease, sarcoidosis, tuberculosis, and syphilis were excluded by clinical examination, glucose tolerance tests, haemoglobin electrophoresis, Mantoux, Kveim, and VDRL tests and chest $x$-rays. All these patients were examined and were broadly categorised as peripheral or mixed types of Eales's disease (Table 1) according to the pattern of retinal vessel closure and neovascularisation seen on fluorescein angiography. An additional case was kindly provided by Professor Patz, of the Wilmer Institute.

The control group consisted of 11 members of the hospital staff who had no ocular symptoms (Table 2), but their fundi were not examined.

A sample of venous blood was taken from each of the patients and controls. Routine haematological parameters were measured including haemoglobin concentration, full blood count, and haemoglobin electrophoresis.

The ODC was determined in all our cases by a spectrophotometric method using washed red cells in a phosphate buffer at $\mathrm{pH} 7 \cdot 00 .^{5}$ The curve was determined for each patient and a control at the same time, though in some cases 1 control acted for 2 patients. The $\mathbf{P}_{50}$ value and Hill's constant ${ }^{6}$ were derived from each curve. The intraerythrocyte level of 2,3-DPG was measured for each sample at the same time as the ODC was determined.

In 2 of our cases (cases 3 and 12) the ODC was 
Table 2 Controls

\begin{tabular}{llllllllll}
\hline Control & Age & Sex & $\begin{array}{l}H b \\
(\mathrm{~g} / \mathrm{dl})\end{array}$ & $P C V$ & Retics & $\begin{array}{l}P_{\text {so }}(\mathrm{mmHg}) \\
n\end{array}$ & $\begin{array}{l}\text { DPG } \\
(\mu \mathrm{mol} / \mathrm{g})\end{array}$ & $\begin{array}{l}H b \\
\text { electropharesis }\end{array}$ \\
\hline 1 & 37 & F & 14.2 & 40.8 & 0.6 & 29.5 & 2.7 & 14.29 & AA \\
2 & 39 & M & 17.6 & 52.1 & 0.4 & 28.75 & 2.6 & 13.2 & AA \\
3 & 35 & M & 15.1 & 45.3 & 0.6 & 29.5 & 2.8 & 13.83 & AA \\
4 & 32 & M & 14.00 & 40.0 & 0 & 31.0 & 2.9 & 14.94 & AA \\
5 & 30 & M & 14.5 & 44.0 & 0 & 27.5 & 2.8 & 12.22 & AA \\
7 & 49 & F & 12.0 & 36.0 & 0 & 30.0 & & 16.33 & AA \\
8 & 33 & M & 14.9 & 45.0 & 0 & 29.5 & 2.8 & 12.87 & AA \\
9 & 33 & F & 14.1 & 42.5 & 0.4 & 30.0 & 2.7 & 14.70 & AA \\
10 & 38 & M & 16.1 & 47 & 2.4 & 30.75 & 2.8 & 12.94 & AA \\
11 & 32 & M & 14.7 & 44 & 0 & 30.5 & 3.0 & 11.54 & AA \\
\hline
\end{tabular}

$\mathbf{P}_{50}$, washed red cells at $\mathrm{pH} 7 \cdot 00$; normal $29 \cdot 5-32 \cdot 0 \mathrm{mmHg}$. $\mathrm{n}$, Hill's constant, normal 2.6-2.9.

also determined for whole blood by a microtechnique (P. D. Wimberley, personal communication). In the additional case provided by Professor Patz the ODC was determined for whole blood by the Hem-O-Scan auto analyser (Aminco).

\section{Results}

Tables 1 and 2 summarise the clinical and haematological findings in our 15 patients and 11 controls respectively. Comparison of the 2 groups (Table 3 ) showed that the $P_{50}$ values were significantly lower in patients with mixed but not in those with the peripheral types of Eales's disease. The haemoglobin and 2,3-DPG levels were not significantly different.

The $\mathbf{P}_{50}$ values for whole blood were also low in 2 of our patients (cases 3 and 12, Table 4) and also in Professor Patz's patient (Table 5).

\section{Discussion}

Patients with Eales's disease may be considered to have neovascular retinopathies of unknown aetiology. Although the fundamental cause of the retinal neovascularisation is not known, there is considerable evidence for a hypoxic process. ${ }^{78}$ If this process is operative in Eales's disease, we must explain the cause of the underlying retinal hypoxia.

Patients with Eales's disease are usually fit young men whose disease is apparently confined to their retinal vessels. Other vascular systems do not appear to be affected, which suggests that it is not a disease of the blood vessels themselves.

Alternatively, Eales's disease could be due to
Table 3 Comparison of the patients and controls in Tables 1 and 2

\begin{tabular}{|c|c|c|c|c|}
\hline & $\begin{array}{l}\text { Number } \\
\text { of cases }\end{array}$ & $H b \mathrm{~g} / d l$ & $P_{50} m m H g$ & $\begin{array}{l}D P G \\
\mu \mathrm{mol} / \mathrm{g}\end{array}$ \\
\hline \multicolumn{5}{|l|}{ Cases: } \\
\hline Mixed & 8 & $15 \cdot 6 \pm 1 \cdot 2$ & $28 \cdot 5 \pm 0 \cdot 7$ & $12 \cdot 95 \pm 2 \cdot 22$ \\
\hline Peripheral & 7 & $14 \cdot 4 \pm 1 \cdot 6$ & $29 \cdot 4 \pm 1 \cdot 5$ & $14 \cdot 27 \pm 1 \cdot 87$ \\
\hline Both & 15 & $15 \cdot 0 \pm 1 \cdot 5$ & $28 \cdot 9 \pm 1 \cdot 2$ & $13 \cdot 56 \pm 2 \cdot 1$ \\
\hline Controls & 11 & $14 \cdot 8 \pm 1 \cdot 4$ & $29 \cdot 8 \pm 1 \cdot 0$ & $13 \cdot 66 \pm 1 \cdot 35$ \\
\hline \multicolumn{5}{|l|}{ Compare*: } \\
\hline $\begin{array}{l}\text { Mixed vs. } \\
\text { controls }\end{array}$ & & NS & $P<0.005$ & NS \\
\hline $\begin{array}{l}\text { Peripheral vs. } \\
\text { controls }\end{array}$ & & NS & NS & NS \\
\hline $\begin{array}{l}\text { Both vs. } \\
\text { controls }\end{array}$ & & NS & $<0.05$ & NS \\
\hline
\end{tabular}

*Wilcoxon rank sum test. NS, not significant.

Table 4 Details of whole blood oxygen affinity in 2 of our patients

\begin{tabular}{clll}
\hline Case & $P_{50}(\mathrm{mmHg})$ & $n$ & Bohr shift \\
\hline 3 & 23.8 & 2.0 & \\
12 & 25.0 & 2.0 & -0.55 \\
\hline
\end{tabular}

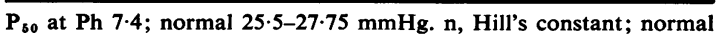
2.6-2.9.

Table 5 Professor Patz's patient

\begin{tabular}{llllll}
\hline Age & Sex & $\begin{array}{l}\text { Type of } \\
\text { Eales }\end{array}$ & $\begin{array}{l}\mathrm{Hb} \\
(\mathrm{g} / \mathrm{dl})\end{array}$ & $\mathrm{PCV}$ & $\begin{array}{l}\mathrm{P}_{50} \\
(\mathrm{mmHg})\end{array}$ \\
\hline 53 & $\mathrm{M}$ & Mixed & 17.6 & 55 & 22.7 \\
\hline
\end{tabular}

$\mathbf{P}_{50}$, whole blood at pH $7 \cdot 4$; normal $26 \cdot 5$. 
changes in the blood which affect the retina only owing to the special nature of its circulation and high metabloic requirements. Eales's disease is usually bilateral, which also implies a systemic condition.

The similarity between some cases of Eales's disease and sickle cell retinopathy suggests a haematological aetiology. Haemoglobin electrophoresis is usually normal, although occasionally abnormal haemoglobins are found (case 8, Hb D, and cases 4 and 10, $\mathrm{HbF}$ ).

Acanthocytosis in patients with Eales's disease has been reported. ${ }^{9-11}$ This is an abnormality of the erythrocytes where there are thorny protuberances on the surface membrane. Acanthocytes may be more rigid than normal erythrocytes and obstruct the small retinal blood vessels, as occurs in sickle cell disease. Acanthocytosis was not noted in our patients.

Argarwal et al. ${ }^{12}$ found that in 61 out of 70 cases of Eales's disease the oxygen content per gram of haemoglobin was reduced. Their patients had normal electrophoresis, but unfortunately they did not report the haemoglobin concentrations.

An observation that the haemoglobin concentration tended to be higher in patients with Eales's disease than in a control group with uveitis (E. S. Perkins, personal communication) suggested that this relative polycythaemia could be secondary to impaired oxygen release from the red cells. We therefore investigated the ODC in our patients.

In our cases the ODC was determined by a spectrophotometric method using washed red cells in isotonic phosphate buffer at $\mathrm{pH} 7 \cdot 00$. This method showed that the mean $\mathbf{P}_{50}$ values were $29.4 \pm 1.5 \mathrm{mmHg}$ in the patients with the peripheral type of Eales's disease, $28.5 \pm 0.7 \mathrm{mmHg}$ in the patients with mixed retinopathy, and 29.8 \pm 1.0 $\mathrm{mmHg}$ in the control groups. Compared with the controls the $\mathbf{P}_{50}$ value was significantly lower in the patients with the mixed type of Eales's disease $(P<0.005)$ but not in the patients with the peripheral form of Eales's disease.

This method for determining the ODC is particularly suited for detecting haemoglobin abnormalities, but metabolic causes for shifts in the ODC may be missed. Therefore in each case the intraerythrocyte level of 2,3-DPG was measured at the same time as the ODC was recorded. The mean level of $2,3-\mathrm{DPG}$ was $13.56 \pm 2.1 \mu \mathrm{mol} / \mathrm{g}$ in the patients with Eales's disease and 13.66 \pm 1.35 in the control groups. There was no significant difference between the 2,3-DPG levels in the 2 groups, which suggests that there was no metabolic cause for a shift in the ODC.

Nor was there any significant difference between the haemoglobin levels of the patients and the controls. This was not in keeping with Professor Perkins's earlier observation that there was a relative polycythaemia in patients with Eales's disease.

The ODC for whole blood is a more physiological expression of oxygen affinity and would be likely to show changes due to abnormal metabolism. Two of our patients (cases 3 and 12) had their whole blood curves determined by a micromethod (Wimberley, personal communication), and Professor Patz's patient had his ODC determined for whole blood by the Hem-O-Scan analyser (Aminco). All 3 cases had mixed retinopathy and low $P_{50}$ values for whole blood at pH 7.4 (Tables 4 and 5).

Although our patients all have the diagnosis of Eales's disease, it is likely that they represent several different conditions. Those with the peripheral type of clinical picture resemble sickle cell disease, and this suggests an obstructive aetiology. These patients did not have significantly different $P_{50}$ values when compared with the control group, whereas the patients with the mixed type of Eales's disease resembling diabetic retinopathy had significantly lower $P_{50}$ values $(P<0.005)$. However, this degree of increased oxygen affinity is not physiologically significant but may reflect an intrinsic abnormality of the red cells. Erythrocyte metabolism has 2 main functions: firstly, to carry and deliver oxygen to the tissues, and secondly to maintain the biconcave shape of the cell which gives it the necessary flexibility to negotiate the fine capillary channels. The low $\mathbf{P}_{50}$ values in some of our patients may simply be an expression of altered erythrocyte metabolism. It would be interesting to know if erythrocyte rigidity or membrane proteins are abnormal in Eales's disease.

We are grateful to the surgeons at Moorfields Eye Hospital for permission to investigate their patients. We thank Dr A. Winder for his advice and encouragement and Dr P. D. Wimberley, who measured the whole blood oxygen dissociation curves in 2 of our patients. Thanks are also due to Dr J. D. Buckley for statistical analysis, Mr K. Sehmi for the illustrations, Dr M. F. Goldberg for advice, and Miss C. Willoughby for typing the manuscript.

\section{References}

1 Eales $\mathrm{H}$. Cases of retinal haemorrhages associated with epistaxis and constipation. Birmingham Med Rev 1880; 9: 262-73.

2 Eales $\mathrm{H}$. Primary retinal haemorrhage in young men. Ophthalmic Rev 1882; 1: 41-6.

3 Duke-Elder S. System of Ophthalmology. London: Henry Kimpton, 1967: 10: 222-36.

4 Mausolf FA. The Eye and Systemic Disease. St. Louis: Mosby, 1975: 179-94.

5 Dacie JV, Lewis SM. Practical Haematology. 5th ed. London: Churchill Livingstone, 1975: 228.

6 Hill AV. The possible effects of the aggregation of the 
molecules of haemoglobin on its dissociation curves. J Physiol 1910; 40: IV-VII.

7 Henkind P. Ocular neovascularisation. Am J Ophthalmol 1978; 85: 287-301.

8 Shilling JS, Kohner EM. New vessel formation in retinal branch vein occlusion. $\mathrm{Br} J$ Ophthalmol 1976; 60: 810-5.

9 Kahán A, Kahán IL, Benkǒ A. Acquired acanthocytosis and myclophthisis in a case of Eales's disease. $B r J$ Ophthalmol 1963; 47: 632-7.
10 Jain IS, Kanwar GS, Das KC. Study of red cell morphology and abnormal haemoglobin in the causation of Eales's disease and other vitreous haemorrhages. $J$ All India Ophthalmol Soc 1970; 18: 111-7.

11 Nath K, Gogi R, Vaid RL. Central retinal vein thrombosis in Eales's disease. Oriental Arch Ophthalmol 1971; 9: 156-7.

12 Agarwal LP, Batta RK, Mohan M. Eales's disease. Oriental Arch Ophthalmol 1963; 1 : 268-73. 